\title{
Democracia, justiça e direitos humanos: 'pontos cegos' do discurso humanista na era dos mercados
}

\author{
Carlos V. Estêvãoi \\ Universidade do Minho, Portugal
}

\begin{abstract}
Resumo
Apresenta-se neste artigo a relação complexa entre o novo humanismo, consentâneo com o novo espírito do capitalismo atual, e os conceitos de democracia, direitos humanos e justiça. De modo particular, o autor pretende tornar visíveis os pontos cegos que o discurso humanista atual esconde, porque colocado ao serviço de lógicas de mercado. O artigo finaliza com uma proposta de um outro humanismo, que contribua para reverter criticamente esta situação e para redignificar a democracia, os direitos e a justiça.
\end{abstract}

Palavras-chave

Novo-humanismo; Democracia; Direitos; Justiça

\section{Introdução}

Hoje, a democracia, os direitos humanos e a justiça são centrais nos discursos das políticas públicas internacionais, exigindo-se cada vez mais o seu aprofundamento e a sua ampliação, ainda que as práticas que ocorrem em alguns lugares do globo pareçam ir em sentido contrário tal como alguns discursos subsidiários da caverna dos mercados e da globalização neoliberalizada.

$\mathrm{Na}$ verdade, em muitas regiões, a democracia aparece infligida por investidas que a querem colocar do lado da "pós-democracia", extremamente 
útil à ordem do mercado, o que leva alguns teóricos a questionar-se se a democracia deveria, por exemplo, ser considerada ou não um direito humano (Ramcharan, 2008) e, de modo mais radical, se se justificaria continuarmos a falar em humanismo.

Por sua vez, os direitos humanos, embora sejam considerados naturalmente como um dos pilares da ordem mundial contemporânea, fornecendo políticas e contribuindo para a ordem pública, quer internacionalmente quer nacionalmente, têm sido incapazes de superar discordâncias quer em torno da sua fundamentação, estrutura, justificação, origem e amplitude, quer também em termos da sua relação com a justiça e a democracia. Nesse sentido, uma das questões pertinentes que poderia colocar-se seria precisamente a da utilidade dos direitos humanos.

No respeitante à justiça, ela tem vindo a ser defendida cada vez mais na sua pluridimensionalidade, característica esta que lhe dá um cariz de uma certa anormalidade, com a (des)vantagem de a tornar mais adaptável mas também mais funcional aos mercados, à custa, logicamente, da substantividade da democracia e dos direitos. E aqui se coloca a mesma questão: que relevância para o bem-estar de todos e da saúde democrática do sistema político pugnar por uma justiça tão maleável, tão plástica, que tudo parece justificar?

Além do que ficou dito, há que reconhecer que na relação da justiça com os direitos os desencontros são vários e nem sempre é fácil articular estes dois conceitos, embora muitos dos consensos em redor da sua natural articulação se teçam a partir da ideia de que qualquer teoria dos direitos humanos implica sempre uma teoria de justiça distributiva ou que os direitos humanos derivam das regras sociais necessárias para assegurar que os interesses básicos de todos os indivíduos sejam satisfeitos (ver Macleod, 2005). Outros autores, imbuídos da mesma preocupação, apresentam a relação entre justiça e direitos humanos de uma forma ainda mais ampla: os direitos seriam naturalmente os garantes da justiça social ou os instrumentos de realização de conceções compreensivas de uma vida boa.

Perante todas as vicissitudes por quem tem passado a relação entre democracia, direitos humanos e justiça, a atual ideologia do humanismo, visível em discursos de pendor político, económico, social e cultural, tem emergido para muitos como uma espécie de bússola para recolocar esta 
trilogia nos seus devidos lugares, mas de uma forma sui generis, que implica a sua ressemantização para melhor corresponder aos desafios atuais. Por outras palavras, a onda do que aqui é apelidado de novo humanismo traz consigo evidências que, na sua perceção imediata e próxima, acabam por construir uma realidade e uma verdade (e dominações também) coerentes com o novo espírito do capitalismo tardio, escondendo simultaneamente pontos cegos, ou seja, outras realidades, outras conexões, outras verdades, não conformes com a atual ordem económica e financeira e o modo como a democracia, os direitos humanos e a justiça aí encaixam.

\section{0 discurso humanista dos nossos tempos}

Um dos modos mais expeditos de apregoar aos quatro ventos a nossa fé na democracia, nos direitos humanos e na justiça é integrá-los num conjunto bem ordenado, envolto num discurso humanista em que o Homem assuma uma posição central.

Com efeito, é difícil rebater a argumentação daqueles que fundamentam as suas posições sobre os direitos e a justiça e mesmo sobre a democracia a partir dos pressupostos filosóficos do humanismo, ainda que não se saiba muito bem, por vezes, o que se entende por humanismo ou de que humanismo estamos a falar.

Esta ignorância (ou ocultação), contudo, não impede de se invocar o santo nome do humanismo para produzir um discurso coeso e aparentemente convincente, em torno da democracia, dos direitos humanos e da justiça, ultrapassando, ou preenchendo, os pontos cegos que a compreensão crítica destes conceitos poderia suscitar. Será talvez por isso que o atual recurso ao humanismo não passe de mais uma manifestação de ignorância que nos querem impor, ou, então, de um recurso que intenta dispensar-nos de pensar, facto que é perfeitamente funcional ao pensamento único que deriva do atual estádio do capitalismo apresentado, por vezes, como condescendente e compassivo.

$\mathrm{Na}$ verdade, o espírito do capitalismo atual nunca deixou cair a bandeira do humanismo. Pelo contrário, sempre a desfraldou aos quatro ventos, mas num sentido que, de modo nenhum, pode ser confundido com a orientação do humanismo (filosófico) clássico. 
O denominador comum de todas as variantes do humanismo é, efetivamente, o convencimento de que o ser humano é em si mesmo um valor e de que deve ser tratado como tal. A própria palavra o inculca: humanismo significa a doutrina do primado do Homem, a afirmação e defesa do humano.

Com efeito, e recorrendo à história das ideias políticas, a origem do humanismo moderno ocidental anda ligada à história da libertação, por ação da burguesia, das estruturas feudalizadas que vincavam a servidão humana. É efetivamente com a ascensão da burguesia e com a fé nas possibilidades da razão que o humanismo, conjuntamente com o otimismo, a crença no progresso e o individualismo, emergem com vigor na racionalidade ocidental. Consequentemente, podemos dizer que o humanismo clássico é o humanismo burguês, caracterizado como racionalista, abstrato, de pendor idealista, que defende que o homem nasce Homem, porque a Razão é o atributo natural de todos os homens; ou seja, o Homem é um ente genérico, um ser abstrato dotado de razão.

Mas existem outros humanismos, com sementes na inquietação dos povos, no inconformismo da juventude e da intelectualidade; ou fundamentado na necessidade de dissolução do indivíduo no impessoal, no anonimato, na vontade de poder, no absurdo, na unidimensionalidade, no conhecimento; ou assente na dignidade do humano e na sua libertação das cadeias da opressão, da dominação, do colonialismo, do capital; ou escurado no personalismo, na valorização do ser em detrimento do ter; ou radicado na imanência do homem na natureza; ou baseado na relação com a transcendência, com o Ser ou com a divindade.

Todavia, eu quero falar aqui de um outro tipo de humanismo, do novo humanismo, assente em pressupostos sintonizados com o "novo espírito do capitalismo" de que falam Boltanski e Chiapello (1999), que integra não apenas os pressupostos do capitalismo, isto é, a ratio do livre mercado, mas também, numa espécie de apropriação crítica da crítica, uma série de argumentos dos críticos do neoliberalismo (o que, consequentemente, torna mais difícil a missão da sua desocultação ou da sua desconstrução).

De facto, o discurso insinuoso do novo humanismo recorre a um arsenal de conceitos lustrosos e a uma argumentação sustentada também do ponto de vista crítico, disponibilizando, deste modo, ao mundo empresarial e mercantil uma retórica atraente a par de uma estruturação discursiva difícil de 
desconstruir. Exemplificando o que acabo de dizer, os dois autores atrás citados elencam os seguintes conceitos, que se comportam como uma espécie de atratores estranhos de novos discursos, de novas qualidades, de novas mensagens, enfim, de novas verdades:

(...) a autonomia, a espontaneidade, a mobilidade, a capacidade rizomática, a polivalência, a comunicabilidade, a abertura aos outros e às novidades, a disponibilidade, a criatividade, a intuição visionária, a sensibilidade às diferenças, a capacidade de dar atenção à vivência alheia e a aceitação de múltiplas experiências, a atracção pelo informal e a busca de contatos interpessoais (...) (Boltanski \& Chiapello, 1999, p. 150).

Acresce a esta lista mais um conjunto sugestivo de outros conceitos, que me permito sugerir: empregabilidade, comunicação, cooperação, qualidade, aprendizagem ao longo da vida, requalificação, coesão social, inclusão, competências, projeto, colaboradores, comunidades de produção, downsizing... todos eles apontando para a prioridade do mundo heraclitiano, da adaptação a condições que fluem permanentemente na transitoriedade, na amoldabilidade, na liquidez (ver Bauman, 2003).

Como é fácil de intuir, deste campo semântico podemos produzir um discurso com todos os ingredientes que satisfaçam uma ementa humanista mais ou menos apetitosa aos espíritos amantes do bom Mercado (mas também do bom Estado e até da boa Comunidade).

Um desses ingredientes, e para começar, é precisamente a "aptidão para a comunicação". Aliás, a comunicação é uma das bases fundamentais das novas capacidades no capitalismo informacional, em que a rede de trabalho é a rede de comunicação entre pessoas. Neste sentido, permanecer em rede é permanecer mais humano e simultaneamente mais produtivo e consumidor. A rede é, pois, uma forma social mais eficiente e justa do que as relações formais tradicionais.

Há, depois, que adicionar um outro composto a esta receita com sabor idêntico: o dos projetos. Com efeito, diz-se que a sociedade atual é uma sociedade de projetos, pelo que o homem atual deve desenvolver a aptidão para ter uma vivência conexionista, a par de uma disponibilidade para se tornar volante, nómada, sem residência fixa, com pensamento rizomático. Por conseguinte, o que importa é envolvimento em projetos, uma vez que estes propiciam outras oportunidades não apenas de conhecer pessoas mas de aprender novas competências e de comprometer-se com novos contratos. 
E agora mais um conceito-aperitivo se torna capital: o das competências, nomeadamente as competências relacionais como: a abertura, o autocontrolo, a disponibilidade e o bom humor, entre muitas outras (ver Boltanski \& Chiapello, 1999; Cardoso, Estêvão, \& Silva, 2006), que nos colocam num patamar superior de grandeza, de empregabilidade, de flexibilidade. $\mathrm{O}$ mesmo se diga das virtudes salvíficas da formação promotora de competências, que qualquer organização e qualquer pessoa, crentes no sortilégio dos mercados, deverão adotar para marcarem a sua diferença crítica face às organizações e pessoas que apenas sobrevivem e que desistiram de apostar na meritocracia global.

Mas a composição da receita não fica por aqui. A coesão social ou mesmo a inclusão funcionam também muito bem como calmantes aos efeitos mais picantes dos seus conceitos aliados, tal como o da competitividade - que quase sempre vêm juntos nos documentos oficiais (por exemplo da União Europeia) -, e deste modo podem servir para atenuar, pela humanização, orientações sociais mais excludentes ou centrífugas que podem resultar do jogo competitivo.

Para servir esta iguaria, importa um novo perfil de indivíduo, naturalmente moldado pela ideologia do compromisso com os pressupostos do espírito do capitalismo, ou seja, pelo "conjunto de crenças associadas à ordem capitalista que contribuem para sustentar e legitimar esta ordem e apoiar, legitimando-os, os modos de acção e as disposições que são coerentes com ele", nas palavras de Boltanski e Chiapello (1999, p. 46).

O problema, então, é levar a que os indivíduos ou os trabalhadores, de preferência dóceis, bons serventes, com mentes e corpos abertos, maleáveis, adaptáveis e bonitos, aceitem que a atividade lucrativa constitui um bem comum para a sociedade, porquanto ela traz progresso material, garante a satisfação das necessidades e favorece a liberdade política. Neste sentido, há que problematizar, entre outras coisas, a distinção entre vida privada e vida profissional: a vida dos negócios e o capital de amizades devem juntar-se, porque tal atitude favorece o êxito e está em sintonia com a necessidade de estar em rede. Ou seja, os afetos, o senso moral e a honra também são importantes para o campo profissional.

Estes argumentos podem, no entanto, revelar-se insuficientes para comprometer os trabalhadores. Há que procurar, por isso, outras justificações 
fora do princípio da acumulação, que legitimem esse seu compromisso. Ora, na fase atual do capitalismo, é precisamente a revalorização do indivíduo, do self, instituído como mágico ou empreendedor/empresário de si próprio, que deve estar na ordem do dia e no centro da nova moralidade, aparentemente mais festiva e também mais líquida.

Então, o indivíduo deve investir nas suas competências para se tornar mais facilmente empregável e, em certo sentido, mais explorável, possibilitando, a outro nível, a naturalização das hierarquias (pessoais, sociais, laborais...) que daí possam resultar. Ele deve, entre outras coisas, tornar-se num verdadeiro aprendente ao longo da vida, pois só deste modo revelará o seu valor, a sua transferibilidade, a justeza do seu lugar na sociedade e no mercado e poderá ser, então, reconhecido naturalmente como justo, enfim, como 'grande' nesta nova ordem institucional, ainda que permaneça numa espécie de servidão dourada a outros senhores (por exemplo, à organização em que trabalha - ver Estêvão, 2012d, p. 118).

Segundo este enquadramento, a aprendizagem ao longo da vida (e da formação), aparentemente amiga de qualquer humanismo, revela-se aqui inequivocamente ao serviço de outros deuses, nomeadamente os deuses do mercado, ou, mais parcimoniosamente, da sociedade do conhecimento. Ela é mais uma construção pedagógica desarticulada do contexto e das questões do conhecimento e da epistemologia, que nos inibe de falar de outros tempos e de outros espaços onde se afirmam outros sujeitos e outras pedagogias (de emancipação, por exemplo).

Há, por conseguinte, na perspetiva do novo humanismo, um imperativo claro que decorre do que atrás foi dito e que tem a ver com a necessidade de cada indivíduo explorar as potencialidades próprias, assumindo a responsabilidade do seu trajeto pessoal e profissional, sem dependência do Estado ou da própria sociedade. Doravante, o que acontecer a cada um não poderá ser interpretado como fruto de qualquer maldição do mercado ou da sociedade mais ou menos empresarializada, mas será devido antes ao mérito ou demérito, ao talento ou não na condução da própria vida, à capacidade ou incapacidade de aproveitar as novas oportunidades de construção de novas subjetividades ligadas agora ao autocontrolo, à motivação, ao compromisso. Isto significa, então, que as próprias 'carências' ou 'deméritos' para concorrer no mercado não podem ser entendidos como "produções históricas de 
discriminações" nas diversas políticas, nomeadamente de emprego e de educação (ver Arroyo, 2012, p. 168), mas resultados naturais do empenhamento individual.

Resulta daqui que esta espécie de universalização da responsabilização individual, em nome também da igualdade (embora "ficcional", segundo Martuccelli, 2001, p. 238) entre todos os indivíduos, pode não passar, ao contrário do que é afirmado pelos ideólogos do novo humanismo, de uma das novas formas de dominação social, na medida em que as responsabilidades que os indivíduos devem assumir estão frequentemente nos antípodas da realização de si, ao mesmo tempo que perdem certas proteções práticas e simbólicas, arcando com o peso da sua existência.

Para terminar este ponto, o novo humanismo corresponde ao humanismo plastificado, com pouca substância, mas que permite encontrar sempre, e com relativa facilidade, um argumento para melhor justificar o nosso lugar no mundo, na sociedade, no mercado. Trata-se de um humanismo particularmente apto para incentivar a manifestação e a criação de um self empreendedor, ou, nas palavras de Rose (1999, p. 161), de uma vida "a tornar-se numa contínua capitalização económica do self" (por formações, competências, preparação para a procura incessante de trabalho). Trata-se, enfim, de um humanismo assente no estatuto da autorreferencialidade, que adquiriu agora uma outra visibilidade e se constituiu, na verdade, na nova forma de governamentalidade neoliberal, indiferente à condição social de cada um.

Daqui resulta, entre outros aspetos, "uma nova economia moral", no dizer de Ball (2006), em que um dos seus princípios é a afirmação de que a competição é natural à pessoa e de que a realização do indivíduo é um assunto fundamentalmente privado, respeitando o livre jogo do mercado e a sua ratio enquanto fundamento de toda a racionalidade. $O$ que verdadeiramente interessa é a satisfação de si próprio, são os resultados, não os princípios.

E é assim que a obscuração do campo de um outro humanismo ('pontos cegos') é preenchido plenamente pelas informações e verdades provenientes das novas realidades em redor e pela nova construção ideológica, ou pelo 'outro olho', do novo humanismo. 


\section{A democracia do humanismo atual}

Vários modelos têm sido apresentados para tornar a democracia mais participativa, mais ativa, mais atuante, mais deliberativa, que propicie aos cidadãos a possibilidade de se tornarem não apenas governados, como acontece com a fórmula representativa da democracia, mas também 'governantes'.

Contudo, a democracia mais sintonizada com o novo humanismo referido no ponto anterior é, na expressão feliz de Crouch (2004), a "pósdemocracia", ponto visível do modo de governar os indivíduos, sem necessidade de preencher a declaração de interesses, objetivamente ao serviço das metas de mercado.

Efetivamente, a pós-democracia, ou a democracia do neoliberalismo, tem os ingredientes necessários à nova ordem do mercado. Ela deve contribuir, desde logo, para que o Estado se torne num aparelho manipulável ao serviço do reforço desta nova ordem, quer através de formas diretas quer por formas mais indiretas ou invisíveis. Dito de outro modo, o Estado deve assumir-se, não como Estado-nação, mas como "Estado-mercado" (Bobbit, 2002, cit. em Ainsley, 2004, p. 499), que, pela sua modéstia ou pela sua imodéstia, deve expandir a nova ordem mercadorizada, substituindo o velho slogan das "oportunidades para ser igual" do Estado-nação pela nova palavra de ordem das "oportunidades para ser desigual".

Por outro lado, o fornecimento de bem-estar pelo Estado a todas as pessoas com propósitos redistributivos não tem, para os defensores da pósdemocracia, legitimidade moral, desde logo porque a imposição da justiça social por parte do Estado é incompatível com a divergência moral da sociedade moderna (ver Picó, 1999, p. 136). Acresce a isto o facto de que o Estado nunca se comportou como um agente neutro e imparcial na distribuição da riqueza e de outros bens sociais como a educação, saúde ou segurança, por exemplo. Agora, como Estado-mercado, ele deve ser oficialmente e ideologicamente indiferente (sempre que convenha) às diferenças, a não ser que estas sejam funcionalmente úteis e lucrativas. É esta, pois, a lógica que deve presidir à estruturação democrática do Estado e da sociedade.

Por outro lado, esta última, na pós-democracia, deve ser recuperada como uma sociedade de empresários ou de empreendedores, que não pode, 
além disso, descurar os interesses dos seus cidadãos preferidos, ou seja, os produtores e os consumidores. Quem não se encaixar nestas categorias não será, portanto, verdadeiramente cidadão ou um democrata. Aliás, neste nosso tempo, é por demais evidente que não é cidadão quem quer, mas sim quem possui um determinado conjunto de títulos e de expectativas. Mesmo a definição de cliente não se aplica a qualquer um. Verdadeiramente quem define o que é ser cliente ou qual o cliente que interessa não são os indivíduos mas cada empresa que fabrica e comercializa os seus produtos para destinatários ou nichos de mercado com perfis traçados previamente; ou seja, em certa medida, o cliente é uma figura fabricada pelo mercado e pelas suas empresas.

Então, na pós-democracia talvez a imagem mais congruente e mais visível de cidadão seja também o pós-cidadão, que possui recursos vários, quer produtivos, quer de consumo, para sê-lo verdadeiramente e comportarse como tal. Obviamente que a grande fatia dos que ficam de fora desta póscidadania podem também ser objeto de medidas especiais de cidadanização, que podem dar-lhes a sensação de permanecerem integrados plenamente neste sistema: produtos de baixa gama, de linha branca ou um dia de saldos fabulosos, por exemplo, ajudam a incutir, de facto, a impressão de que, afinal, todos contam ou de que contam com eles!

Pesem embora estas medidas excecionais, neste tipo de democracia há sempre os irrelevantes, como sejam os desadequados, os contemplativos, os incompetentes, para não falar também dos incapacitados ou dos idosos, dos feios ou dos gordos, sobretudo se eles não forem descobertos por qualquer sector económico como um filão a explorar. Neste, como noutros campos, a exceção pode constituir-se, na verdade, numa ótima oportunidade de negócio ou num verdadeiro nicho de mercado lucrativo, porquanto estes 'diferentes' se tornam "coisas à venda" (expressão de Arroyo, 2012) potencialmente lucrativas.

Torna-se evidente, por esta análise, que os pontos visíveis da pósdemocracia não nos deixam perceber quanto da dignidade de muitos de nós é violada pela subalternização ou mesmo pela centrifugação do sistema oficial por nos considerarem incompetentes ou então sem crédito bastante junto das instituições que regulam a vida económica, social, cultural e política da pósdemocracia para nos considerarem cidadãos de pleno direito. 
Poderíamos ampliar um pouco mais esta leitura colocando-a ao nível do conhecimento que interessa na pós-democracia. Obviamente que o conhecimento técnico ou tecnocrático, por um lado, e os que produzem resultados economicamente rendíveis, por outro, tendem a ser os privilegiados e financiados, até porque trazem bem-estar a toda a sociedade. Isto quer dizer que a pretensa democratização do saber invocada pelo novo humanismo, ao não valorizar verdadeiramente outras formas de saber, ofusca ou omite a relevância de outros olhares, de outras epistemologias, de outras narrativas de emancipação pelo conhecimento ou do conhecimento como reconhecimento (ver Santos, 2007).

Um outro ponto a destacar no novo humanismo é aquele que sublinha o seu bom relacionamento com conceitos tradicionalmente colocados nas posições mais democráticas e substantivas da democracia, como é o caso dos conceitos de participação e autonomia, o que, entre outras coisas, dificulta a sua desocultação crítica.

Ora, sabemos pela sociologia das organizações, por exemplo, que o processo de participação equivaleu historicamente mais a uma técnica ou a uma encenação participativa do que verdadeiramente a uma participação substantiva, colocando-se, objetivamente, ao serviço de uma engenharia social que visava, e visa, sobretudo a eficiência. $O$ mesmo se diga da autonomia outorgada, a partir da década de 60 do século XX (mas com destaque nas duas décadas seguintes), aos trabalhadores e às suas equipas, no sentido de se auto-organizarem para produzir mais e com mais qualidade. $\mathrm{Na}$ verdade, estes processos foram introduzidos segundo uma lógica que apontava para a ressurreição do taylorismo, pela interiorização dos seus pressupostos e das suas formas de controlo, embora com recurso a meios mais humanos e que penetravam mais profundamente na interioridade das pessoas. Então, os apelos retóricos atuais a estes conceitos pela 'neogestão' (preocupada em orientar o mundo do trabalho num sentido mais humano) adquirem no novo humanismo uma nova significação, definhada politicamente, mas permanecendo atraentes para o cumprimento de outras funções como a do autocontrolo ao serviço da produtividade. Outros sentidos de participação e autonomia, mais enriquecedores e emancipatórios da pessoa, continuam, portanto, como pontos cegos do novo humanismo, encarregando-se este de os tornar idênticos, quando emergem, aos que ele manipula. 
Não é inocente, finalmente, que a pós-democracia enalteça e recorra também a processos aparentemente mais democráticos, porque abertos a todos, de controlar a vida das instituições. Se atendermos ao que se passa hoje em dia em muitas organizações públicas, por exemplo, o controlo está presente pelo login e password (ideia de um meu aluno de pós-graduação) ou por plataformas digitais, assumindo, de certo modo, a forma do "sinóptico" de Bauman (1999, p. 60), o qual não precisa de coação para alguém ser vigiado, porque ele "seduz as pessoas à vigilância"; trata-se, assim, de uma espécie de big brother em que todos se vigiam mutuamente (controlo social) e em que até o próprio controlo é controlado.

É por isso que a democracia digital de hoje pode não passar de uma outra expressão da pós-democracia que nos aponta para um novo ser humano: mais autorreferencial e simultaneamente mais conexionista e redial; mais autónomo e ao mesmo tempo mais (auto)controlado e previsível.

\section{Direitos humanos e humanismo atual}

Os direitos humanos têm servido vários senhores, colocando-se não raramente na senda dos comportamentos considerados politicamente corretos, nomeadamente quando estes se abrigam sob os desígnios do humanismo ou, de forma mais visível, sob os auspícios do humanitarismo.

Por outro lado, os direitos humanos tal como ficaram na Declaração Universal de 1948 tenderam a ser interpretados à luz do favorecimento do indivíduo, na linha das preferências ocidentais, menosprezando, segundo alguns pensadores, e em nome da universalização, a sua contextualização e a dimensão coletiva do viver humano, entre outros aspetos.

É por isso que hoje, segundo Matlary (2008), existe um conceito multiuso dos direitos humanos em que a sua valoração se transforma num processo político sujeito a alterações contínuas. Trata-se, por isso, de um processo de fungibilidade dos direitos humanos em que é difícil encontrar critérios morais e valores comuns a todos. Entrou-se, assim, prossegue a autora, numa espécie de relativismo em que o indivíduo se torna a medida de todos as coisas ou, se preferirmos, numa era do homem autorreferencial em que os valores se submetem aos desígnios dos próprios indivíduos, num prenúncio claro do crepúsculo do dever, já vaticinado há tempos por Lipovetsky (2004), na linha do que então apelidou de "neo-individualismo". 
Uma das consequências desta visão é que a compreensão da esfera pública tendeu a reduzir-se e a tornar-se num espaço mínimo e residual, alterando-se, simultaneamente, o 'substrato material' da cidadania e a interpretação dos direitos individuais, passando estes a ser vistos de uma forma particular no sentido da clientelização do papel do cidadão, enquanto a cidadania passou a ser interpretada como um dever de normalidade económica e de mobilidade no mercado.

Constata-se então aqui mais um ponto visível do discurso humanista de hoje, que na sua apelação explícita à defesa dos direitos do indivíduo tende ao mesmo tempo a ocultar o processo de ajustamento dos direitos às exigências e à axiologia de mercado, ainda que com a anuência voluntária das 'vítimas'.

Este ponto pode parecer surpreendente à primeira vista, mas se tivermos em conta, por exemplo, a nova centralidade do discurso político da desigualdade ou da diferença, também em nome do humanismo, verificamos que agora ele passou a promover sobretudo, como afirmam Gamarnikow e Green (2003, p. 219), a "diversidade inclusiva" enquanto se adotam os mecanismos neoliberais para a realizar sob o guarda-chuva do capitalismo social. E daí acrescentarem os autores (p. 210) que os excluídos e os desafortunados passam a ser o foco das políticas de "oportunidade", ao mesmo tempo que, por outro lado, a ênfase passa a estar não tanto na igualização mas na distribuição equitativa de oportunidades para alguém se tornar, ou se identificar, como desigual embora incluído.

Este modo de captar o sentido da inclusão social é coerente com a preocupação de tornar o sistema social e económico mais gerível, mais regulável e aparentemente mais bondoso, evitando desequilíbrios ou a emergência de franjas de população potencialmente perigosas para o bom funcionamento dos mercados. Nesta sequência, a coesão social torna-se, também, uma dimensão indissociável das políticas da competitividade, como é facilmente constatável nas políticas europeias, por exemplo, orientadas primacialmente para o crescimento e para a competitividade. Por outras palavras, a ideologia da inclusão e da coesão social, sendo altamente permeável e sensível aos problemas sociais pode contribuir para apaziguar interesses contraditórios, acalmando o sistema ou protegendo-o de potenciais questionamentos sociais ou políticos. Além disso, pode ter o condão de aliviar a culpa do sistema relativamente à injustiça social 
para a fazer recair sobre as próprias vítimas (devido, por exemplo, à sua incompetência). Finalmente, e sob o nome de uma cultura de tolerância e de valorização da diferença e da diversidade, a ideologia da inclusão e da coesão pode estar a "dissimular a problemática da heterogeneidade e da desigualdade social" (Correia, 1999, p. 108).

Temos, então, que o discurso dos direitos humanos pode servir, como já disse, vários senhores e vários humanismos, incluindo o mais dócil e maleável aos pressupostos do mercado. Ou seja, ele pode servir de autêntico 'cavalo de Tróia' para a invasão da ideologia mercantil, muitas vezes até em nome da defesa dos direitos políticos e civis, como se fossem estes os únicos que interessaria reivindicar e exercer (ver Estêvão, 2012b).

Por outro lado, não é possível ocultar que os direitos humanos ziguezagueiam por vezes ao sabor dos humores políticos ou de políticas geoestratégicas nem sempre confessadas, quer de governos quer de multinacionais (como é o caso das 'sete irmãs do petróleo', por exemplo). $\mathrm{Na}$ literatura dos direitos humanos são recorrentes as referências concretas à intervenção, invasão ou interferência dos países ocidentais em casos específicos de pretensa violação dos direitos humanos por parte de alguns países. A contrastar com esta 'militância' soergue-se ao mesmo tempo um muro de silêncio, de omissões, de neutralidades face às atrocidades cometidas, por exemplo, nos Balcãs (Bósnia e Kosovo) e no Iraque, à limpeza étnica no Ruanda, à sonegação de direitos às mulheres na Arábia Saudita, ao trabalho escravo na China e Bangladesh, à opressão dos curdos na Turquia ou do povo do Sara Ocidental por parte de Marrocos. De facto, a elasticidade multiuso dos direitos é aqui por demais evidente, em nome de conceções oportunistas e economicamente interesseiras de certos países, que se servem do seu poderio bélico para 'pacificar' a seu favor, sob o 'véu de ignorância' dos direitos, certas regiões do mundo.

O novo humanismo, então, é surpreendentemente elástico no atinente aos direitos, porquanto os molda de modo a torná-los em joguetes ao serviço dos interesses mais ou menos imperiais ou neocolonialistas, mantendo aparentemente a sua pureza inicial. Com efeito, a elasticidade do discurso humanista, articulado com a elasticidade da vida social, permite estas veleidades, estes desaforos pelo poder de criar ilusões e de encobrir outras realidades, enfim, outras experiências e estados de dominação. 
Mas poderá defender-se que o novo humanismo dá uma visão mais funcional e concreta aos direitos, permitindo até manter uma plataforma mínima de direitos potencialmente universalizáveis, em vez de uma listagem historicamente marcada, não consensual, como a que consta da Declaração Universal dos Direitos Humanos de 1948. Acrescenta-se que a implementação de alguns dos direitos da referida Declaração seriam até política e socialmente deslocados (como, por exemplo, o direito a férias), havendo necessidade, por isso, de os suprimir para melhor proteger ou reforçar outros direitos. Além disso, esta visão contribuiria para renegar uma certa idolatria universalista dos direitos, prejudicial aos mesmos, cingindo-os ao 'humanamente possível', o que contribuiria para uma perspetiva mais sensata e pragmática, embora mais limitada, destes mesmos direitos.

Mais. Aproveitando o que alguns autores defendem quanto ao desenvolvimento histórico dos direitos humanos e às transformações que ocorrem na nossa sociedade, o novo humanismo tem a oportunidade de reiterar o seu realismo ao afirmar que os direitos têm a ver sobretudo com as forças da globalização e da modernização (forças fiscais, comerciais, culturais e informacionais). Por outras palavras, e como afirma Franck (2001), se os direitos humanos são produtos de desenvolvimentos recentes, ou seja, da industrialização, da urbanização e das revoluções nas comunicações e na informação, o novo humanismo poderá, neste ponto, guindar-se a ideologia universal, cosmopolita, que recobre todos estes aspetos do progresso humano. Além disso, permitiria ultrapassar a velha querela da origem ocidental dos direitos, uma vez que agora se assumiria claramente que as forças atrás referidas (de globalização e de modernização) não são culturalmente específicas.

Não obstante a pertinência desta posição, a questão que se levanta aqui é de saber em que sentido o novo humanismo interpreta os direitos humanos, considerando, ainda, que a globalização e a modernização são, além disso, altamente variáveis, porquanto elas podem ter vários sentidos, alguns mais amigos dos direitos e outros menos, consoante o poder dos Estados, a capacidade de controlo das instâncias de governança globais, o nível de homogeneização cultural, o grau de penetração das economias de mercado, entre outros fatores. Por outras palavras, quer a globalização quer a modernização são altamente ambíguas, embora frequentemente se dotem 
de propriedades propensas à ocultação de uma normatividade congruente com uma ideologia neoliberal e neoconservadora.

Ou seja, o novo humanismo pode parecer mais realista e cosmopolita, mais de acordo com as exigências da nova ordem mundial, ainda que esta assente sobretudo em pressupostos economicistas e financeirizados. Por conseguinte, outras preocupações, outras dicotomias (como regulação/emancipação, por exemplo), oriundas do velho humanismo clássico ou moderno, não passam de quinquilharias guardadas no sótão da memória, com interesse residual. O novo olhar da ciência e da tecnologia (consideradas como bens económicos e não como património da humanidade), do conhecimento útil e produtivo, do pensamento tecnocrático é que deve orientar a nossa visão do ser humano e dos seus direitos. Consequentemente, os direitos humanos emancipados continuarão como pontos cegos, ofuscados, ou então recriados, pelos pontos-luz dos direitos regulados pelos princípios de mercado, que inspiram o novo humanismo.

\section{Justiça e humanismo actual}

Escrevi, noutro trabalho (ver Estêvão, 2009), que, no cenário de um pretenso realismo económico (agora em período crítico em certas zonas do mundo), há uma certa impulsão para a "desformalização" da ideia de justiça social, ou para a sua perceção como oferta apenas de garantias contingentes, ou ainda para a sua minimização na medida em que se limita a cumprir direitos sociais de baixa intensidade, de assistência aos mais desfavorecidos, de neo-pietismo em que as intervenções neste campo obedeceriam a uma espécie de nova subsidiariedade do social: "o público é para os que não podem alcançar o privado" (Alonso, 2000, p. 179).

Penso que hoje, nomeadamente nos países em crise, já nem esta última afirmação é válida! Na verdade, o acesso ao público começa também a ser cada vez mais restritivo, o que pode levar a afirmar que o público está, nos tempos que correm, aberto apenas àqueles que manifestam ser detentores de alguns recursos materiais e/ou de determinado estatuto, devendo os restantes procurar o não-público, o doméstico, o assistencial, o acaso, a fatalidade.

Neste contexto, a justiça social não importa ou importa pouco, valendo apenas a justiça que torna o indivíduo mais eficiente e eficaz e, também, mais 
vendável. Não surpreende, por isso, que nesta fase do desenvolvimento capitalista continue a falar-se em justiça, até porque ela é extremamente funcional ao próprio mercado. E este é mais um ponto cego do discurso do novo humanismo, que não larga a justiça, embora já tivesse abandonado a justiça social.

No mesmo ímpeto, os subtextos de redistribuição tendem, na retórica oficial do discurso neo-humanista, a ser omitidos, muitas vezes a favor de subtextos de reconhecimento (ver Fraser, 2005). Ou seja, como que para equilibrar a balança da justiça cega, aposta-se no prato da justiça cultural, como se as lutas pela justiça social estivessem já ganhas. Nesse sentido, a sobrevalorização de uma dimensão da justiça (neste caso, a cultural) pode constituir-se também num ponto cego do novo humanismo, que nos desvia para outras lutas, deixando o caminho aberto para o verdadeiro inimigo ocupar as nossas trincheiras ou restringir os nossos espaços de ação e de intervenção.

Mas há ainda mais pontos cegos neste discurso quando prossegue na (in)compreensão da (pluri)dimensionalidade da justiça. Se os teóricos mais radicais pretendem ir além da justiça económica e da justiça cultural é necessário reforçar então as defesas, contendo os seus intentos. Por conseguinte, a proposta de uma terceira dimensão de que fala Fraser (2005), relacionada com a justiça política, entendida como representação ou como "paridade participativa", pode configurar-se como problemática para uma pósdemocracia que se dá mal com a politização da política e com a hegemonização de categorias tradicionais como as de classe social. Então, remeter a justiça política para a esfera dos interesses meramente teóricos, relevando ao mesmo tempo a sua fraca produtividade e a sua tendência escusadamente conflitual, pode ser sinal de sensatez política, e que o novo humanismo não deixa de subscrever.

Tal como disse em cima, no novo humanismo persiste a preocupação pela justiça, mas não de uma justiça qualquer. Ele apadrinha claramente a justiça de pendor industrial e mercantil (ver Estêvão, 2004), cuja preocupação primordial não é a igualdade mas antes a condução das vidas e das mentes pelos parâmetros de custo e benefício, de eficácia, de maximização da eficiência mercantil, independentemente dos efeitos de exploração, de competição e de desigualdade que geram. Aliás, estes efeitos são omitidos ou 
catalogados como colaterais, pelo que o novo humanismo continua a defender a justiça empresarialista e mercantil como realização humana, que sintoniza o indivíduo com o que hoje verdadeiramente interessa e que permite tecer os contornos realistas da verdadeira justiça; neste caso, o cidadão autenticamente justo será aquele que se tornou relevante ou ajustado na ordem institucional do mercado, isto é, o cidadão eficiente e vendável.

Como é fácil de ver, a justiça empresarialista e mercantil tem relações profundas e privilegiadas com o mundo das organizações. E tanto é assim que os vários estudos que têm vindo a ser publicados neste domínio, de pendor sobretudo psicossociológico, reportam as suas vantagens, designadamente na ótica da eficiência organizacional. Nesse caso, praticar a justiça organizacional pode significar que alguém se tornou vulnerável aos objetivos da organização e que não só contribuiu para cumprir as metas de produção como excedeu as expectativas. Será este o verdadeiro trabalhador de qualidade, ordeiro, controlado, eficiente, respeitador, disciplinado, que vai permitir à organização fazer mais com menos; será este, enfim, o verdadeiro cidadão organizacional (Estêvão, 2012c).

Se este perfil corresponde a uma verdadeira humanização do trabalhador, tal continua a ser um ponto cego do atual humanismo, sobretudo quando é sabido que a qualidade, juntamente com a flexibilidade e as equipas de trabalho se constituem com frequência, dentro das novas condições em que se processa a gestão dos recursos humanos, no "tripé da subjugação" (Legge, 1995).

Enfim, a noção de justiça manipulada pelo novo humanismo (que preferencialmente opta pelo conceito de equidade por uma maior vinculação à produtividade económica e à contribuição individual) tende a provocar, mesmo quando invoca a ética e a responsabilidade, a erosão dos valores da autoconfiança, da colegialidade, da solidariedade, da justiça do cuidado, embora as ideologias do empreendedorismo, da iniciativa e da responsabilidade individuais, das competências, mobilizadas agora, possibilitem um olhar mais doce e mais humano para as justiças que oprimem e instrumentalizam.

Para concluir este ponto, a essência da justiça do mercado advém da sua capacidade de nos tornar naturalmente felizes pela posse, consumo e intercâmbio de bens e produtos. Isto significa que recolocar no plano da visão 
formas ditas extremas de justiça social, que se prendam, por exemplo, com o combate às formas institucionalizadas de dominação e opressão nas relações de trabalho, na tomada de decisões ou no plano cultural, como nos propõe Young (1990), pode equivaler ao gesto de distanciamento crítico que poderá dar-nos uma visão mais completa e radical da realidade social e política

\section{Para um outro humanismo}

Parece-me evidente que as vicissitudes por que tem passado a democracia exigem um esforço na sua revitalização, enquadrando devidamente os direitos humanos e a justiça na era dos mercados, sem serem adulterados na sua essência.

Assim, e a título descritivo e meramente exemplificativo, poderemos deparar-nos com várias conceções de democracia que apontam para processos de construção e defesa dos direitos distintos assim como para conceções diversificadas de justiça.

No sentido de visualizar mais facilmente as relações entre estes conceitos, observe-se o Quadro I.

\section{Quadro I - Democracias, direitos humanos e justiças}

\begin{tabular}{|c|c|c|}
\hline DEMOCRACIAS & DIREITOS HUMANOS & JUSTIÇAS \\
\hline Democracia tecnocrática & Empresarialista & $\begin{array}{l}\text { Meritocrática } \\
\text { (ser justo = ser eficiente) }\end{array}$ \\
\hline Pós-democracia & Mercantil & $\begin{array}{l}\text { Individualista } \\
\text { (ser justo }=\text { ser vendável e competitivo) }\end{array}$ \\
\hline $\begin{array}{l}\text { Democracia deliberativa } \\
\text { comunicativa }\end{array}$ & Cidadã & $\begin{array}{l}\text { Cívica e solidária } \\
\text { (ser justo= ser cidadão) }\end{array}$ \\
\hline $\begin{array}{l}\text { Democracia como direitos } \\
\text { humanos }\end{array}$ & Emancipatória & $\begin{array}{l}\text { Cosmopolítica } \\
\text { (ser justo= cidadão do mundo e para o mundo) }\end{array}$ \\
\hline
\end{tabular}

Pelo quadro torna-se claro que estes três conceitos, embora interrelacionados, não coincidem no seu sentido. Por outras palavras, a democracia não se identifica com a justiça nem com os direitos, nem a justiça é completamente sobreponível ao conceito de direitos humanos. 
A este propósito, e reportando-me apenas à relação entre estes dois últimos conceitos, considero, por exemplo, que a fundamentação da democracia nos direitos assentes na justiça é, ou pode ser, mais radical que a fundamentação da democracia nos direitos humanos explicitados na Declaração Universal dos Direitos Humanos de 1948. Na linha de Rawls (1993), por exemplo, tal proposição é perfeitamente compreensível e defensável.

Para além deste debate (e desta polémica), um outro cenário que defendo como solução que dignifica a democracia, os direitos e a justiça é aquele que no Quadro I coloca a democracia "como direitos humanos" (Goodhart, 2005), uma vez que reposiciona a democracia no campo das preocupações e da luta pelos direitos compreendidos na sua essencialidade emancipatória e pela justiça social em qualquer parte do mundo. Aqui, ser justo equivale, na verdade, a ser cidadão solidário, que investe continuamente na cidadanização dos direitos de todos, tendo em vista a emancipação. $O$ contexto político-social e cultural propício ao seu desenvolvimento é o da "demoglobalização", como alguns propõem, construída a partir de baixo, em interdialogação e cordialidade, com as diversas forças sociais e as múltiplas comunidades políticas.

Também eu considero que só na conversação bottom-up, em consensos sobrepostos, construídos primeiramente em cada comunidade política concreta e depois entre comunidades, é possível progredir numa conceção mais consistente de justiça global e, ao mesmo tempo, construir uma plataforma consensualizada de direitos universais, universalidade esta que não poderá ser, por isso, uma universalidade de retas paralelas, mas antes uma "universalidade de confluência" (Herrera Flores, 2000), construída a partir de baixo.

Trata-se então de uma proposta mais cosmopolítica de democracia, de justiça e dos direitos, que não deixa de assumir igualmente as formas do respeito, do amor e da solidariedade, que constituem o tripé do reconhecimento de Honneth (2003), ao serviço do incremento de interações em que os sujeitos se interessam reciprocamente pelos seus percursos de vida diferenciados, porque se valorizam entre si e, deste modo, se experienciam a si próprios como valiosos para a sociedade e para o mundo. Será por este caminho que passará, na minha perspetiva, a construção da 
eticidade democrática e cosmopolítica e da própria democracia entendida como direitos humanos (Estêvão, 2012b, 2012a).

\section{Conclusão}

Muitos têm ingenuamente acreditado nas virtudes intrínsecas do novo humanismo para regular, de forma quase automática, a vida coletiva e, noutro plano, o próprio liberalismo enquanto sistema económico e político.

Por outro lado, muitos outros estão convictos de que o modelo representativo, muito formal e pouco substantivo da democracia tradicional já não serve. Então, haverá que encontrar outros compromissos, outras definições, outros recursos. Torná-la mais adaptável, mais flexível, mais líquida, mais desterritorializada é, pois, o desafio que a democracia contemporânea deve enfrentar para melhor corresponder ao carácter elástico do mundo social contemporâneo, para melhor enquadrar a plasticidade dos estados e das experiências de dominação ordinárias estruturantes do nosso quotidiano e para melhor combater a crítica do desencantamento, da inautenticidade da vida quotidiana no cosmos capitalista (ver Boltanski \& Chiapello, 1999 e também Martuccelli, 2001).

A este propósito, e como os dois primeiros autores alertam, muitos esquecem-se da capacidade regenerativa do capitalismo, que aproveita, de facto, as críticas que lhe são dirigidas (por exemplo, de alienação no trabalho ou de mecanização das relações humanas) para se renovar, encontrando, deste modo, pontos de apoio moral que lhe faltam e dispositivos de justiça que o tornam mais humanizado.

Não obstante a importância da denúncia da 'obscuração do campo visual' por parte do novo humanismo aqui descrito, há que ir mais além e anunciar um outro humanismo, que não só exercite a ética da crítica à governamentalidade estabelecida pelos interesses e exigências do Mercado, mas também a ética da justiça e dos direitos, a ética do cuidado, do reconhecimento e da solidariedade, quer em relação aos que nos são próximos, quer aos que nos são distantes.

E assim se fará luz, creio, sobre os 'pontos cegos' que na ideologia oficial do humanismo atual não emergem ou são ocultados por outros conceitos (ou pelos mesmos conceitos, embora ressemantizados), 
mobilizando-nos para um outro olhar sobre a democratização da sociedade, a justiça e o empenhamento nas lutas pela dignidade própria e do outro. Assim emergirá um outro humanismo, com contornos de um verdadeiro contrahumanismo alternativo, assente nos direitos humanos e na sua narrativa emancipatória e onde todos seremos reconhecidos como verdadeiros "sujeitos políticos e de políticas" (ver Arroyo, 2012, p. 330).

\section{Referências}

Ainsley, P. (2004). The new 'market-state' and education. Journal of Education Policy, 19(4), 497-514.

Alonso, L. E. (2000). Ciudadanía, sociedad del trabajo y estado de bienestar: Los derechos sociales en la era de la fragmentación. In M. P. Ledesma (Comp.), Ciudadanía y democracia (pp. 159-191). Madrid: Editorial Pablo Iglesias.

Arroyo, M.(2012). Outros sujeitos, outras pedagogias. Petrópolis: Editora Vozes.

Ball, S. (2006). Sociologia das políticas educacionais e pesquisa crítico-social: Uma revisão pessoal das políticas educacionais e da pesquisa em política educacional. Currículo sem Fronteiras, 6(2), 10-32.

Bauman, Z. (1999). Globalização: As consequências humanas. Rio de Janeiro: Zahar.

Bauman, Z. (2003). A modernidade líquida. Rio de Janeiro: Zahar.

Boltanski, L., \& Chiapello, E. (1999). Le nouvel esprit du capitalisme. Paris: Ed. Gallimard.

Cardoso, C., Estêvão, C. V., \& Silva, P. (2006). Competências transversais dos diplomado do ensino superior. Guimarães: Tecminho.

Correia, J. A. (1999). As ideologias educativas em Portugal nos últimos 25 anos. Revista Portuguesa de Educação, 12, 81-110.

Crouch, C. (2004). Posdemocracia. Madrid: Taurus.

Estêvão, C. V. (2004). Educação, justiça e democracia. S. Paulo: Cortez.

Estêvão, C. V. (2009). Educação, globalizações e cosmopolitismos: Novos direitos, novas desigualdades. Revista Portuguesa de Educação, 22(2), 35-52.

Estêvão, C. V. (2012a). Democracia, justiça e participação. In M. J. Casa-Nova, A. Benavente, F. Diogo, C. V. Estêvão \& J. T. Lopes (Orgs), Cientistas sociais e responsabilidade social no mundo actual (pp. 93-105). V. Nova de Famalicão: Húmus.

Estêvão, C. V. (2012b). Direitos humanos, justiça e educação na era dos mercados. Porto: Porto Editora.

Estêvão, C. V. (2012c) (Org.). Políticas de formação, ética e profissionalidade. Curitiba: CRV. 
Estêvão, C. V. (2012d). Políticas e valores em educação. Repensar a educação e a escola pública como um direito. Vila Nova de Famalicão: Húmus.

Franck, T. (2001). Are human rights universal? The rise of cultural exceptionalism. Foreign Affairs, Vol. 80, Issue 1, 191, 623-642.

Fraser, N. (2005). La justicia social en la era de la política de la identidad: Redistribución, reconocimiento y participación. In N. Fraser \& A. Honneth, Redistribución o reconocimiento? (pp. 17-88). Madrid: Morata.

Gamarnikow, E., \& Green, T. (2003). Social justice, identity formation and social capital: school diversification policy under New Labour. In C. Vincent (Ed.), Social justice, education and identity (pp. 209-223). London: Routledge Falmer.

Goodhart, M. (2005). Democracy as human rights: Freedom and equality in the age of globalization. New York: Routledge.

Herrera Flores, J. (2000). El vuelo de Anteo. Derechos humanos y crítica de la razón liberal. Bilbao: Editorial Desclée de Brouwer.

Honneth, A. (2003). Luta por reconhecimento. A gramática moral dos conflitos sociais. S. Paulo: Ed. 34.

Legge, K. (1995). Human resource management. London: Macmillan Press.

Lipovetsky, G. (2004). O crepúsculo do dever. A ética indolor dos novos tempos democráticos. Lisboa: Ed. D. Quixote.

Macleod, A. (2005). The structure of arguments for human rights. In D. Reidy \& M. Sellers (Ed.), Universal human rights (pp.17-36). New York: Rowman \& Littlefield publishers, inc.

Martuccelli, D. (2001). Dominations ordinaires: Explorations de la condition moderne. Paris: Balland.

Matlary, J. H. (2008), Derechos humanos depredados. Hacia una dictadura del relativismo. Madrid: Ediciones Cristiandad.

Picó, J. (1999). Teorías sobre el Estado del bienestar (3 ${ }^{\mathrm{a}}$ ed.). Madrid: Siglo Veintiuno.

Ramcharan, B. (2008). Contemporary human rights ideas. New York: Routledge.

Rawls, J. (1993). Uma teoria da justiça. Lisboa: Editorial Presença.

Rose, N. (1999). Powers of freedom: Reframing political thought. Cambridge: Cambridge University Press.

Santos, B. S. (2007). Para além do pensamento abissal: Das linhas globais a uma ecologia dos saberes. Revista Crítica de Ciências Sociais, 78, 3-46.

Young, I. (1990). Justice and the politics of difference. Princeton: Princeton University Press. 
202 Carlos V. Estêvão

DEMOCRACY, JUSTICE AND HUMAN RIGHTS: BLIND SPOTS OF HUMANIST DISCOURSE IN THE AGE OF MARKETS

\section{Abstract}

The author presents the complex relation between new humanism, congruent with the spirit of current capitalism, and concepts of democracy, human rights and justice. Accordingly, the author aims to highlight the blind spots that current humanists hide in their speech, which is placed at the service of the logics of market. The paper finishes with a proposal of another type of humanism, which contributes to critically reverse this situation and to redignify democracy, human rights and justice.

Keywords

New humanism; Democracy; Rights; Justice 
DEMOCRACIA, JUSTICIA Y DERECHOS HUMANOS: PUNTOS CIEGOS DEL DISCURSO HUMANISTA EN LA ERA DE LOS MERCADOS

\begin{abstract}
Resumen
Presentamos en esto trabajo la compleja relación entre el nuevo humanismo, en consonancia con el nuevo espíritu del capitalismo de hoy, y los conceptos de democracia, derechos humanos y justicia. En particular, el autor tiene la intención de hacer visibles los puntos ciegos que el discurso humanista actual oculta, ya al servicio de la lógica del mercado. El artículo concluye con una propuesta de otro humanismo, que contribuya a revertir críticamente esta situación y redignificar democracia, los derechos humanos y la justicia.
\end{abstract}

Palabras clave

Nuevo humanismo; Democracia; Derechos; Justicia

Recebido em agosto, 2013

Aceite para publicação em outubro, 2013

i Centro de Investigação em Educação, Instituto de Educação, Universidade do Minho

Toda a correspondência relativa a este artigo deve ser enviada para: Carlos V. Estêvão, Rua dos Carvalhos, $n^{\circ}$ 3, Priscos, 4705-564 Braga, Portugal. E-mail: cestevao@ie.uminho.pt 